\title{
Shaping the Living Body: paradigms of soma and authority in Thomas Hanna's writings
}

\author{
Margherita De Giorgi \\ Università di Bologna - Bologna, Italy
}

ABSTRACT - Shaping the Living Body: paradigms of soma and authority in Thomas Hanna's writings - This article outlines some features of the discursive strategies adopted by Thomas Hanna in order to legitimate Somatics - as well as his own method - in the eyes of the scientific community. The notion of soma and the representations of its functions will be recognized at the core of this issue. In order to stress the enduring risk of dogmatism of the scientific rhetoric to our days, as well as their influence on the configuration of somatic discourses, I will be mainly referring to Isabelle Ginot's radical epistemology and Martha Eddy's critical perspective.

Keywords: Hanna. Somatics. Radical Epistemology. Soma-aesthetics. Scientific Discourse.

RÉSUMÉ - Donner Forme au Corps Vivant: des paradigmes du soma et de l'autorité dans les écrits de Thomas Hanna - Cet article se propose de tracer les contours d'un ensemble de stratégies discursives à l'œuvre dans les écrits Thomas Hanna, mises en place pour légitimer le champ de la Somatique - ainsi que sa propre méthode - dans le milieu scientifique. La notion de soma et les représentations de ses fonctions sont mises au centre de cette question. Pour mettre en évidence le risque constant de dogmatisme dans la rhétorique scientifique, ainsi que son implication dans la construction des discours somatiques, les références fondamentales de l'analyse sont constituées par l'épistémologie radicale d'Isabelle Ginot et par la perspective critique de Martha Eddy.

Mots-clés: Hanna. Savoirs Somatiques. Epistémologie Radicale. Soma-esthétique. Discours Scientifique.

RESUMO - Dando Forma ao Corpo Vivo: paradigmas do soma e da autoridade em escritos de Thomas Hanna - Este artigo delineia alguns aspectos das estratégias discursivas adotadas por Thomas Hanna para legitimar a Somática - assim como seu próprio método - aos olhos da comunidade científica. A noção de soma e as representaçóes de suas funçóes serão reconhecidas no âmago desta questão. Para enfatizar o persistente risco de dogmatismo da retórica científica, assim como sua influência na configuraçáo de discursos somáticos, recorre-se principalmente à epistemologia radical de Isabelle Ginot e à perspectiva crítica de Martha Eddy.

Palavras-chave: Hanna. Somática. Epistemologia Radical. Soma-estética. Discurso Científico. 


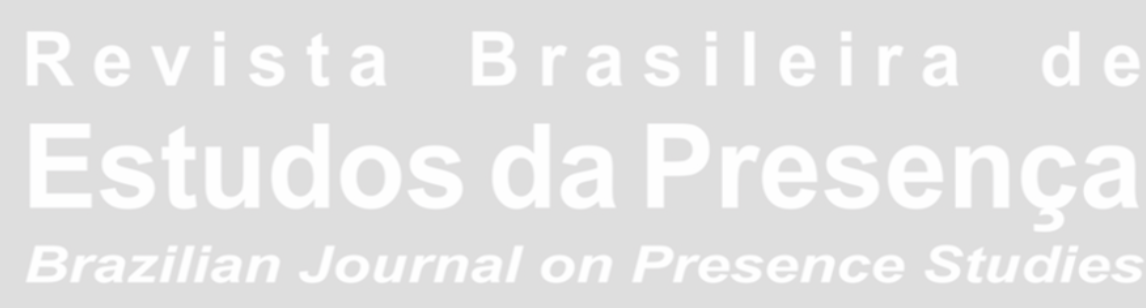

ISSN 2237-2660

\section{Introduction}

Looking closely at practitioners' writings as well as to the scientific sources and speculations, after more than one year of orientation I found that choosing to investigate the so-called somatic field by means of its written sources does not necessarily generate a definition of my research by itself. This has become clear to me as soon as I realized that a historical and critical perspective on Somatics is not quite, or not exclusively, concerned in the definition of Somatics as an institutionalized field - yet neither as just a constellation of movements and independent approaches. In both cases, the necessary conditions for a preliminary investigation are provided, but they eventually prove insufficient and rather unsatisfactory. Academically speaking, one first issue at stake may be referred to as a research on somatic knowledge 1 and the process of its theoretical and institutional validation within its varied community. Definition being the goal, here one step forward is taken. By pointing to the multiple entities informing it, as well as their emerging from corporeal experiences, the expression somatic knowledge partially inhibits the temptation of reducing a number of practical methods into a single theoretical model. Besides, it helps to understand them as originating from irreducible and seemingly individualistic experiences, differing in time and space, and stretching from the late $19^{\text {th }}$ century to our days. Surely, Somatics' phenomenological plurality seems confirmed, thanks to a growing number of experiential accounts of the exploitation of somatic practices in the context of performing arts and education (Fortin; Long; Lord, 2002; Fortin; Vieira; Tremblay, 2009; Weber, 2009). The main focus of such writings often consists in demonstrating the relevance Somatics disciplines have in preventing injuries and refining the performers' sensitive skills. Nevertheless, until recently, few of them have been trying to express the epistemological side of somatic approaches, and their configuration whenever applied in other contexts of care (Bottiglieri, 2013; Bottiglieri; Ginot; Salvatierra, 2013; Ginot, 2012, 2013). Overall, a critical analysis of what induces somatic discourses to presume the (homogeneous) functioning of these disciplines has just appeared ${ }^{2}$.

An investigation of some theoretical somatic texts and of the studies on the development of Somatics as a movement, whose 
authors are also practitioners, may provide some clarifications. When evaluating Somatics as a comprehensive yet eclectic movement, the first step is to face contradictions, tensions, and epistemological incoherencies. To do so, I will pinpoint some of those aspects which have been so far considered as fundamentals, or rather strategic arguments, in the introduction of Somatics' theorizations within the written, scientific, and academic discourse. Rather than seeking exhaustiveness, such a choice allows highlighting partialities and dogmatism, but also facts, names, and ethical convergences. All of these elements effectively endeavor the articulation of current identity politics, and the circulation of knowledge based on bodily practice. In short, such an inquiry can offer an outline of the strategies adopted by somatic practices to face Euro-American economies of knowledge and market, since at least the outburst of the 1970s counter culture, to which ideology Somatics seems to look back.

\section{On Model and its Necessity}

As Isabelle Ginot observed, Somatics eventually lacks solid conceptual definitions of its own general features (Ginot, 2010, p. 13). Apparently, the source of the problem comes from within the somatic discourses produced by each practice, sometimes circulating in the somatic field even beyond their own communities of practitioners, disciples or patients ${ }^{3}$. In order to explain and legitimate themselves, somatic practices are generally both based on and endeavoring tautological definitions and "thoughts of the universal" (Ginot, 2010, p. 23). Thus, their endogenous discourses engage ambivalent bonds with the rhetoric of science, their founders' research and personal involvement, the case studies, and the metaphors (or examples) they present (Ginot, 2010, p. 13-17). This problem tangles when it encompasses published texts - namely, the somatic pioneers' writings - which generally claim to prove scientific validity for the practices they profile:

The function of science within somatics is to foster belief. Whereas somatic practice incessantly exposes difference in and the immaterial and elusive nature of sensing, scientific discourse inscribes vertiginous individual experience into a large sphere whose uniformity promotes generalization. Somatics induces to believe in the 'scientific', universal, and 'provable' nature of experience, in order to provide a stable 
collective context for what is fundamentally an unstable, highly individualized experience (Ginot, 2010, p. 15).

Moreover, subtracted from a generating context, the somatic becomes a conceptual a priori, a category embracing the logic and economy of simplification, as much as it aims at conveying the ecology of practice into the discourse. Especially evolutionistic theories are generally used to attain this scope (Ginot, 2010, p. 14-15).

This article approaches this epistemological issue through the study of some written somatic discourses. I will attempt to unveil a number of discursive strategies (or techniques, to quote Ginot) linked to the extraction of Somatics from its empirical context, as well as a number of specific issues related to the nature of each strategy. More specifically, in the following case studies I will stress the enduring use of these techniques in current outlines of the somatic field, on one hand, and the articulation and use of its main philosophical and epistemological components on the other. To do so, I will refer to some recent historical-critical studies and, mainly, to a number of somatic writings hailing to its first theorization in the 1970s.

The opening case concerns Martha Eddy's ${ }^{4}$ depiction of Somatics' cultural genesis, early development, and institutionalization. By the perspective of somatic activism and ecology, I will recall Eddy's studies in the central section of the text, where a radical analysis of Thomas Hanna's early writings is attempted. I will focus on Hanna's linguistic shift in the expression of its theoretical foundations, that is, soma as living body and Somatics as the exclusive field approaching its study by a subjective viewpoint ${ }^{5}$ (Hanna, 1976, 1985).

Ginot's radical epistemology of endogenous somatic discourses provides the main methodological instruments for this analysis, allowing to focus on the imprints that both Eddy's and Hanna's activism leave on their text. Ginot's proposal consists in the articulation of the inquiry by three axes: the analysis of the discourses' modes of efficacy, or the imaginary of the body subtended by the writings; the inquiry of their status as "alternative knowledge"; the individuation of normative shifts of this alternative model (Ginot, 2010, p. 22). I will focus, though not exclusively, on the last two axes and stress the role of science, as well as the authority of the somatic pioneers, in the process of shaping Somatics as a unified field.

Moreover, the discursive contradictions will be considered as acceptable as "fleeting moments" of understanding (Eddy, 2009, p. 


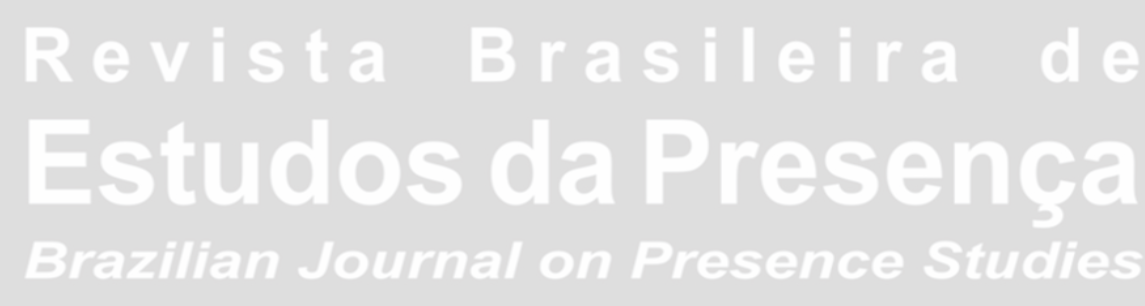

23-25), and therefore worked upon by an analytic approach. In other terms, acknowledging the continuity between somatic practice and somatic (written) discourse, I consider Eddy's, and overall Hanna's texts as specific forms of founding writings. I thus will evaluate them not only by their adequacy to the academic standards of validity, but also by their performing nature, and the hermeneutic consequences they produce addressing to the receiver - for as Ginot observes, their discursive techniques are deeply enrooted in the systems of beliefs informing both the context and the words of somatic practice:

Somatic discourses, therefore, must be read as performative discourses, situated in a precise context and targeting thereby an equally precise efficacy. In this regard, somatic discourses do not stand apart from the practices that engender them. Their value is not universal but isolated, and their validity can only be measured by the effect they produce on a given subject, in his/her encounter with a given context. Somatic discourses constitute physical techniques, just as do the practices from which they emanate. [...] endogenous somatic discourses have a strictly performative function as techniques of the body, and their sole function is to contribute to the efficacy of somatic gesture ${ }^{6}$ (Ginot, 2010, p. 18).

Far from implying that writing may ever be devoid of contingency, I intend to keep my subjective viewpoint as much explicit as possible in the articulation of the text - this being at least the most immediate ethical reaction to the complexity of the investigation itself. In the end, is the somatic field the object of this study, or is it the fictional process of the construction of its identity? My strategic posture will be stepping backward from dual dialectics and accepting "[...] the 'both-and' ambiguity of somatic process" (Hanna, 1976, p. 31-32), even facing its social collective expressions. The choice of a short selection of sources will hopefully allow the articulation of more refined arguments, while providing an overlook dismissing any encyclopedic exhaustiveness.

\section{Intentions: the holistic fiction of lineage}

The field of 'somatics' is barely a field. If necessarily seen as one $[. .$.$] , how did individual experiences of, and with, the$ living body become a field? (Eddy, 2009, p. 6).

In this section, I will introduce Martha Eddy's historical perspective on the early development of the somatic field. I will 
stress the relevance of some arguments Eddy provides in order to explain the multicultural dimension of Somatics, as well as its highly diversified identity. Subsequently, I will focus on Thomas Hanna's writings and highlight the presence of similar positions. The main unverified, if not untouched issue of both sources is the coexistence of highly individualistic experiences and their systemic bond through space and time, seemingly provoking the same struggles and ideals. I intend to start by the short quote at the opening of this chapter, where Eddy explains her ambivalent viewpoint and formulates a question whose answer she eventually suspends.

In the first place, the adverb Eddy adopts - "barely" - is quite interesting: it signals a tension between all these elements and arouses the curiosity for something more, laying latent in the discourse. Somatics appears to be a field, yet per se it functions as if it were not, relying on a number of isolated experiences. Though resisting a spatio-temporal determination a posteriori because of her ecological perspective, Eddy seems to come to an answer - or a personal fundamental dimension of Somatics? - by approaching a suprahuman scale (Ginot, 2010, p. 15):

Illnesses, physical limitations, [...] spiritual practices through travel and transmigrations [created] separately but in a common period of time new views of human behavior [...] love of movement and curiosity about the physical body [which combined into] the independent formation of various systems of bodily inquiry in Europe, the United States and Australia. The positive outcomes of these investigations gave credence to the process of finding answers to bodily needs and communicative desires through internal bodily awareness (Eddy, 2009, p. 6).

The implicit process at stake in this excerpt is not confirming the international - rather than multicultural - sources of early Somatics. It consists in implicitly admitting the existence of an invisible, enduring resonance of values and intents between individuals who actually did not encounter, or otherwise did not confirm an actual, prolific collaboration. More precisely, the intensity of this bond seems not to be ascribed to pragmatic, collective research and practice, not even within each pioneer's small community of disciples or patients. Following this assumption, seemingly invisible, ecological agents would induce the attunement of subjective sensitiveness, individual attitudes, and other still unveiled factors. In the next paragraphs, it 
will become clearer that such a thesis was at the core of early Somatics, at least during the first decade of its existence, from conception to foundation.

Yet, Eddy's quote may suggest an opposite hypothesis: Somatics is not a field by itself, but it eventually functions as it were. If this were the case, a precise intention, namely the desire of realizing a predefined project would produce a fictional but effective convergence within those isolated experiences, subjective sensitiveness, and individual attitudes. This is what appears in Thomas Hanna's research and commitment, too, thus revealing its primary source in the author-and-practitioner's aims, and an epistemological belonging to his/her performative signature.

Nevertheless, both these contradictions eventually seem worth of attention, as long as they are understood as starting points towards the resolution of specific issues, be it theoretical legitimation, technical standards, juridical status or ethical, controversies. In fact, just as much as subjective experience, scientific background, ethical and philosophical concerns, professional issues and resolutions are operating and coexisting processes, shaping the configuration of somatic disciplines thanks to individual as well as collective engagement. All of them configure forms of activism the founding practitioners had also to assume and confront with since the very beginning. Activism and issues, in turn, have been changing in time - by this perspective, Eddy's inquiry will be soon a valuable reference.

Somatics' novelty and divergence from legitimate protocols required responding with solid plans, inventiveness, and a constant negotiation with the competitive economies of market and knowledge. All of these materialistic aspects, which are actually part of the practitioner's professionalism, are usually omitted in the pioneers' writings. Yet, in our case, they implicitly re-emerge as discursive techniques through Eddy's concern of Somatics' normative shifts, and the prominent avoidance of cultural delimitation of the somatic dimension in Hanna's use of the notion of soma in his early writings on Somatics. Hanna's discursive strategies of that period (approximately from the late 1960s to the second half of the 1980s) triggered several aesthetical and ethical issues, which will be retraced in the contemporary institutional expression of Somatic Movement, Therapy, and Education referring to Eddy's research. Nevertheless, 
Hanna's ought to be depicted as one strategy among others. He indeed shaped a form of practice and an ideology on pre-existing cultural phenomena that eventually became dominant; yet, his own engagement in the foundation of the somatic field, though much better chronicled, was probably influenced by a variety of sources and proposals, coming from others activists and practitioners. Hanna supposedly recollected and resumed them, but, following the posture he adopts in his articles, he probably also spoke in their behalf and molded, or inhibited other possible expressions and potentials ${ }^{7}$. Therefore, rather than sketching the development of somatic as a whole, I will outline how Hanna happened to be particularly effective and influent in creating his perspective, as well as the fiction of Somatics as a uniform entity.

In his most important volume Bodies in Revolt (1970), Thomas Hanna cleverly defined Somatics first and foremost as an epistemological shift, a mode of thinking produced by a transformation of one's quality of awareness (Hanna, 1985), rather than a group of pre-existing methods to merely assemble and institutionalize. Such a move appears to be far from casualty. In fact, it is even conceivable that a somatic movement had never existed in itself before Hanna introduced this notion in the late 1960s. Moreover, he would explicitly refer to a number of practitioners as somatic pioneers far after the development of their method, and even the death of most of them (Hanna, 1995, p. 351). In contrast, as I will shortly explain, a variety of movements and technical approaches would actually be part, or external complements, of the upcoming institution of Somatics ${ }^{8}$.

In the 1970s Hanna coined the term 'somatics' to describe and unify these processes under one rubric. Philosophers and scholars in the late twentieth century helped to forge the new field of Somatic Education. [...] the global communication explosion, and the cultural shifts of the 1970s, spurred a veritable boom in 'somatics' (Eddy, 2009, p. 7).

On one hand, practitioners and thinkers would look for models, references, and authorities around which recognizable features and conscious theoretical discourses could be articulated. Traditions, paradigms, and identities would be (re)traced, (re)configured as long as it was felt necessary. On the other, inherent dialectics and 
critical approaches would grow in the following decades, especially influenced by feminist theories (Eddy, 2000, 2009; Haraway, 1988, 1991; Stengers, 2003). Such processes triggered most evidently the social and political side of the somatic practices and their ethics, producing further transformations and differentiations of the field. Today, the most recent institutional expression of the somatic field is ISMETA, the International Somatic Movement Education and Therapy Association, established in 1988 in California as the International Movement Therapy Association (IMTA). Again, though functioning as an organized entity, trying to define ethical and technical standards, the association is far from being exhaustive of the somatic phenomena, as well as from being unitary. Since the early 2000s, Eddy has been refining her inquiry, by the realization that "Now lineages are more complicated" (Eddy, 2002, p. 47):

In 2004, I identified that there are three branches of the somatic world - somatic psychology, somatic bodywork, and somatic movement (Eddy, 2004). I contend that dance professionals have especially driven the development of somatic movement and the field of Somatic Movement Education and Therapy (SME\&T) [...] Just from Bonnie Bainbridge Cohen alone, six new [somatic movement] systems in four different countries have been born (Eddy, 2009, p. 7-19).

According to Eddy, "[...] there are over 37 different somatic movement certification programs today" (Eddy, 2009, p. 15). What should then be the definition of soma and Somatics today or, more correctly, which are the possible definitions I should take into consideration? In fact, to provide a useful, enriching outline of the phenomenon, such a research has to deal first and foremost with the deterministic obsession itself. Models, necessities, and intentions operate, in the somatic field as elsewhere, as culturally determined, biased epistemological strategies. This is seemingly how (inter) subjective inquiries were eventually able to produce and develop methods and functional aesthetics, each one responding to a specific socio-cultural frame.

\section{Authority and Activism}

The key to access to a complex system and understand its functioning can be found in the details. Acknowledging the fact that 
the terms soma and somatic themselves had never been introduced in the pioneers' writings, nor had they acquired their current specific meaning before Hanna's definition, some preliminary considerations ought to be expressed. First of all, strong authority - a strong individual (self)assertion and imprint - seems to be at the source of the somatic field as we know it. It is now clear that, in Hanna's view point, the existence of legitimating authorities is of vital importance for the self-determination of the field. If so, how does his attitude as practitioner and author influence somatic discourses?

At least in the early phase of Somatics' institution, Hanna's theoretical writings aim at functioning as a center of gravity for an extreme variety of practices, practitioners, and researches. All these begin to orbit around in a more or less spontaneous way, in order to be given voice and legitimation, as well as to participate to a seemingly collective project. This aspect brings to our discourse a first order of ethical implications, and practical complications that will be soon considered:

[...] regarding the dissolution of any potentially monolithic views of the history and etiology of 'somatics' as well as somatic movement applications in dance [it has to be noted that] a part of the historical development of the field of 'somatics' involved choices to acquire a type of meta-view; a view that stands back from distinct cultures and investigates the individual organism separate from any identity other than that of being human (Eddy, 2002, p. 2).

It is undeniable that Hanna intended to respond to such a need for organization by creating common aesthetics, ethics, and legitimate form of alliance. This was in fact his form of activism and the primary scope of his early theoretical writings. On the other hand, in so doing, Hanna endeavored and catalyzed the enactment of essentialist postures, persisting to our days?

These issues may be briefly resumed, at this early stage, as the paradoxical coexistence of intentions I highlighted so far. Whereas the older and most traditional sources of the somatic field show a greater interest in (re)defining both bodily essence and a system of norms and values as universa ${ }^{10}$, more recent studies of the field especially in Somatic Movement Education - understand them, or their application, as instances of normalization and ethnocentrism (Eddy, 2009; Ginot, 2010); therefore, somatic activism privileges their 
disempowering via the reconfiguration of the practices. It is of great importance to note that, in this case, equal action is often addressed to mainstream as well as somatic practices themselves:

It is my belief that somatic practice, characterized by a first-person experience within a cultural context, can encourage a move toward a more politicized stance that enables a critique of existing dance, arts, and educational institutions, as well as the agency and empowerment of individuals. In current practice, in my observation, some somatic disciplines are taught in a style that could be characterized as authoritarian. Indeed, many holistic, indigenous practices exist or co-exist within hostile authoritarian cultures. It is imperative that we begin to question whether these practices actually bring wholeness to the individual or to the group, given the structures within which they are taught (Eddy, 2002, p. 14).

This relevant and yet inevitably generalized overlook finally expresses the main struggles that somatic activism encounters by relying on the ground of still undertheorized and unquestioned discursive methodologies (Ginot, 2010, p. 13). Facing the history of the somatic field thus consists first and foremost in a problematic encounter with its plurality, and an even more difficult choice - or reinvention - of narrative techniques. The issue at stake is political. Both of these dynamics endeavor desires, dogmas, and biases that have been concealed in the institutionalization of the disciplines. All of these elements mutually interfere and reshape one another, as days and researches go by.

\section{Metaphors}

I liken it to a field of wildflowers with unique species randomly popping up across wide expanses (Eddy, 2009, p. 6).

The methodological choices I have just profiled imply the effort to read between the lines of the official cartographies, enlightening the logics as well as the partialities informing this peculiar field. For the same reason, this paragraph begins with Martha Eddy's definition of Somatics, which I deliberately omitted in the quote at the opening of this essay ${ }^{11}$. Eddy's image is more than an effective and gracious example. It conceals some interesting references to notions such as nature, inter-independence, ecology, and globalization, profiling a 
configuration far from being neutral. The image of the wildflowers "randomly popping" through a vast environment seems to recall an interpretation we have already encountered - cultural development as the spontaneous, or so-called natural result of individual choices, moved by the invisible intentions of an ecological, yet transcendent entity. Additionally, daring to draw this perspective further, the use of the metaphor in the construction of the discourse appears very meaningful in itself. It is reliable to a rich field of cognitive and neuroscientific inquiries on learning and language, which became more and more relevant from the early 1980's and evidently influenced somatic researches, from Hanna's to Eddy's. In works as George Lakoff and Mark Johnson's (Lakoff, 1987; Lakoff; Johnson, 1980), as well as, later on, Francisco Varela and his collaborators' (Varela; Thompson; Rosch, 1993), the notion of metaphor is conceived as the paradigm of cognitive experience, as an embodiment process, or embodied action ${ }^{12}$.

All of these authors generally define embodiment as the immediate appropriation of a perceptive experience through physiological processes, and its translation into more and more articulated units of abstract thought. Significantly, in the same period Hanna's research was devoted to the development of a legitimated - and legitimating - scientific literature, in order to give birth to the institution of somatology, the holistic physiology of somatic processes (Hanna, 1976, p. 33). All of these authors, and especially Hanna, found a common philosophical background in the American Pragmatists, as well as in the Continental Existentialism and Phenomenology (Hanna, 1991a, p. 14-15). All these references lie quite implicit in Eddy's image. Yet, according to Eddy, they constitute a strong background in the second and third generation of somatic practitioners and activists (Eddy, 2000, 2002, 2009), producing a cultural and ideological way both of seeing things and seeing through things. Such a way to look at, and respond to an already disperse heritage informs the complexity of this field, its ideological contradictions, and ambivalent relationship to scientific authority. In fact, whether consciously or not, the ideological posture of the practitioner and the activist shapes the bodies of their communities: intentions become attitudes, invisible agents which reconfigure scopes, means and results, even in stable technical frames. In these terms, it is possible to look at Somatics as an ecological approach: 
This century's use of the term 'somatic' (as a model of holism derived from bodily wisdom), was intended by early thinkers [...] to also be applied to external action and social change. Hanna [...] defined somatic study as a study of the living body existing in relationship to at least five somatic assumptions. One such assumption regards 'somatic ecology' in which the soma demonstrates interdependence with the environment, 'social as well as physical' (Eddy, 2000, p. 1).

Yet, this evidence does not simplify the study of the field. In these lines, Eddy recalls once more Hanna's article The Field of Somatics, which appeared in the first edition of the Somatics journal in 1976. Whereas, in a restricted sense, it seems correct enough to read Hanna's posture as ecologic, it ought to be noted that the notion of ecology he endeavored appears to acquire a quite different meaning from Eddy's gendered and poststructuralist perspective. In fact, they diverge inasmuch as, for Hanna, ecology would justify the naturalization of sociocultural progress and the universalization of the somatic dimension. Hanna's living body would be more and more abstracted from a situated milieu, as long as the scientific attitude and rhetoric was adopted in his somatic literature. Only the diagnostic examples he reported in his late works seem to rely to real individuals, yet most of them are briefly depicted through their therapeutic relation with Hanna and they interact with the practitioner in a seemingly abstract context (Hanna, 2004). In short, multiculturalism and global influences (Eddy, 2002) would be misunderstood or neglected in order to support a scientific reductionist point of view. Up to the early 1990s and beyond, such a posture would support the authoritarian methods Eddy reports as an activist. Interestingly, she also explains how the disempowerment of this reductionism would begin with the second generation of somatic leaders, "[...] women [who] have bridged the fields of somatic education and dance ${ }^{13}$ " (Eddy, 2009, p. 16).

\section{Bio-scientific Transcendence, or the Ecological Appetite: (r)evo- lution versus activism}

In order to understand the process of naturalisation of the soma, as well as the appropriation of scientific authority in Hanna's philosophical and political assumptions, it is possible to start reviewing his scientific publications from 1970 up to the early 
1990s. Since the very beginning, the use of Darwinian concepts of evolution and progress confirms a quite different attitude from Eddy's ecology. Soma seems to be observed from an abstract, suprahuman, bio-holistic point of view:

[...] soma tends toward autonomy and independence of its environment while tending toward appetite for and dependence upon its environment - social as well as physical. The functions and structures of opening and closing create the apertures of interchange with the environment (Hanna, 1976, p. 32).

By the same perspective, to Hanna, soma is also at the core of the 1960s cultural revolution, produced by what he understands as a (r)evolutionary shift, a new balance between technologies and human awareness of personal as well as collective needs (Hanna, 1985, p. 15-17). As a consequence of the ultimate development of human selfawareness, not only bodily models, but the very individual bodily experience and social behavior were ought to transform:

And so, there we are: le conflit des générations, the 'generation gap' is upon us; except that the conflict is not between generations but between traditional and mutant cultures. [...] our creation of a new kind of environment is, by consequent adaptation, creating a new kind of human being whose behavior is groping to adapt to that environment. Thus, this behavior will be new and different: it will be 'misbehavior' (Hanna, 1985, p. 18-19).

Such "misbehaviour", recalling the 1960 social and political counterculture, eventually diverges from Eddy's activist perspective. Where the latter is concerned in working with and within a sociocultural environment, the revolution of the somas in Hanna's perspective is slightly inscribed in a dualistic opposition between an old and a new generation or, more precisely, between an old and "a new kind of human being". Here it is possible to seize continuity to Moshe Feldenkrais' positivism. Feldenkrais copiously referred to a generalized necessity to rebalance the relationship between social rules, educational systems, and the human potential. In Hanna's perspective, such dialectic between individual and social values was about to be dismantled by a growing community of individuals, sharing a renewed ecological bond to their environment. Two controversial elements are the premises to such discourse: on one hand, a claim to reveal scientific dogmas as socio-politically biased in character; 
on the other, a sort of re-appropriation of the natural essence of the bodily-self. Through a re-evaluation of perceptive experience, individuals could eventually embody the true self, lying beneath cultural constraints. In fact, nature was conceived as the multilayered, physical (thus true) essence of reality and human race. As a consequence, thanks to their scientific competence and the success of their practices, both Feldenkrais and Hanna enthusiastically proclaimed to be able to address, hence to talk on behalf of, all human kind with no exceptions: "We are just beginning to understand the somatic way of thinking which is to say that we are just beginning to understand what it really means to be a human being and to live in the full promise of that somatic reality" (Hanna, 1985, p. II).

\section{The Feldenkrais - Hanna model: toward a somatic essentialism}

It is then possible to stress a strong influence of Feldenkrais' approach to science in Hanna's, confirmed by a mutual bond between the two practitioners. In fact, both of them played a main role in establishing the foundations of the Somatic Studies in the United States and beyond. It is worth noting that between 1976 and the early 1980s, when Hanna was devoting himself to the development of the somatic field, Feldenkrais was already internationally renowned. Coming from engineering studies and a Ph.D. in Physics, he had also a strong background in martial arts, having been a Jiujutsu practitioner and having earned the black belt in Judo in 1936 (Eddy, 2009, p. 13). Hanna hailed from the academic environment too. After a degree in Theology "[...] as an atheist" (Hanna, 1991c, p. 50) at the University of Chicago, he had become chairman of the Philosophy Department at the University of Florida. Bodies in Revolt hails to the sabbatical he devoted to the study of neurology at the Medical School. He would later note that his own philosophical passion would lead him to psychology and psychotherapy, and eventually to become "[...] a philosopher who works with his hands" (Hanna, 1991c, p. 51). Hanna was already a scholar and author of several essays on philosophy when he encountered Moshe Feldenkrais in the United States and began to follow his practice. Deeply impressed by his work, in 1975 he organised the first Feldenkrais method training in the US and founded the Novato Institute for Somatic Research and Training with his wife Eleanor Criswell. He would subsequently 
develop his own method, presented in 1989 as Hanna Somatics or Hanna Somatic Education ${ }^{\circledR}$, which he would teach until his death in 1990. The basis of their authority then can be found in a mutual support, in a similar scientific competence and personal charisma. These factors would mark their own writings and the epistemological core of the early Somatics.

\section{Strategies of Settlement: the body of truth}

Following Feldenkrais' perspective, Hanna claimed that the somatic approach supported self-determination of the individual through bodily practice. However, such a claim was based on the essentialist stance that Somatics holds the key to universal awareness and health. This biased, authoritarian turn eventually sharpened with the institutionalization of the somatic field and the development of Hanna Somatic Education ${ }^{\circledR}$. Giving shape to the soma and its functions was at the core of this strategy, and this is why its definition in Hanna's works follows an interesting path. In around fifteen years, soma shifts from vitalistic aesthetics to categorical abstraction and scientific rhetoric. In Bodies in Revolt, translating it from the ancient Greek as living body, Hanna describes soma as "[...] expanding and contracting, accomodating (sic) and assimilating, drawing energy and expelling energy. Soma is pulsing, flowing, squeezing, and relaxing." (Hanna, 1985, p. 35). Hanna refers to it as "bodily being" and not just as body, a word that reminds him of "[...] a piece of meat - a slab of flesh laid out on the butcher's block or the physiologist's work table, drained of life and ready to be worked upon and used" (Hanna, 1985, p. 35). Moreover, rejecting the Cartesian separation between body and mind, Hanna sets the foundations for a phenomenological localisation of the soma in a "here and now" from which it can never subtracted (Hanna, 1985, p. 34-35). Therefore, in his eyes, soma is not discernable through scientific categorisation, but rather via sensitive, intuitive intelligence.

However, in the next decade, Hanna would turn this perspective into a quite radical parascientific attitude. Aiming at reaching out to a growing community of followers and students, Hanna's interest shifts from what the soma is to how it works and is perceived, thus declaring "Somatics is the field which studies the soma: namely the body as perceived from within by first-person perception. When a 
human being is observed from the outside - i.e., from a third-person viewpoint - the phenomenon of a human body is perceived" (Hanna, 1995, p. 341). Excluding one, early exception (Hanna, 1973, p. 9-10), rather than evaluating them as specific semantic units of the same corporeal entity, in Hanna's theory soma and body are rigidly opposed: they are results of different cognitive modes. In spite of being theoretically coequal, "Failure to recognize the categorical difference between first-person observation and third-person observation leads to fundamental misunderstandings in physiology, psychology, and medicine" (Hanna, 1995, p. 341-342).

Hanna's opinion on traditional scientific approaches marked the greater part of his most important articles in the decade between 1975 and 1985 and beyond. Yet, his position remained quite ambiguous until the late years of his career. At times, Hanna spoke of a simple difference of methodology, which would seem solvable through the integration of the somatic perspective (the holistic, first-person point of view). Almost as often, though, the critical stances get more radical and the language sharpened, exposing a generalized un-ethical posture in biosciences, which Somatics was willing to avoid, if not to correct.

The life sciences in general and the sciences of physiology, psychology, and medicine in particular lack valid grounds for what they assert to be established fact and sound theorizing exactly to the degree that they ignore, wilfully or innocently, first-person data. To avoid evidence that is 'phenomenological' or 'subjective' is unscientific. To dismiss such data as irrelevant and/or unimportant is irresponsible (Hanna, 1995, p. 343).

An evident absence of corrections to such strong statements suggests that Hanna was deliberately adopting an aggressive attitude as a strategy of legitimation. In contrast, since his early writings, Hanna explicitly looks back with admiration to a number of scientists and thinkers. The first and most evident example is Bodies in Revolt, which Hanna devotes for the most part to an outline of the works of so-called somatic scientists and somatic philosophers ${ }^{14}$. Significantly, all over the essay, the bond between their research and his own is turned into an assumption of lineage. Moreover, such relationship is configured in order to legitimate the somatic perspective as a scientific one: Hanna himself attributes a somatic quality to their 
intelligence and, thus, to their intuitions. Once more, it is possible to profile a strong fictional discourse in Hanna's writing, willing to retrace a direct, legitimated scientific tradition. Even more relevantly, in so doing, the whole discourse appears to be placed in the shade of an evolutionary progress of human awareness ${ }^{15}$. Later on, the same attitude comes forward, which I understand as paracolonialist:

It is this same acceptance of the 'both-and' ambiguity of somatic process that allowed the gap between psychology and physiology, psychiatry and physical medicine to close up through the extraordinary therapeutical work of Wilhelm Reich, Raknes, Feldenkrais and Lowen. [...] It is the discovery of the functional-structural integrity of the somatic field that allowed Western scientists and scholars to make the belated discovery that the Asian martial arts and bodily disciplines of judo, aikido, t'ai chi, karate, yoga and tantra were predicated solidly on a somatic theory and not upon a religious pretense (Hanna, 1976, p. 31).

The paracolonialist posture seems to operate as a common principle both in the appropriation of tradition(s) and the rejection of the scientific objectivism. In both cases, the struggle between body and soma acquires a central role, since it reveals a political side. On one hand, its substance is epistemological, since it deals with the transformation of corporeal representations, as well as the scientific advancement in the industrial and post-industrial era. On the other, it becomes the metaphor for an ideological competition between legitimate and precarious practices, which in the first generation of somatic activism seems to be still more influenced by economic survival than by ecologic adaptation (Eddy, 2000, 2009).

A rather influent case is Bonnie Bainbridge Cohen's use of the term somatization. Traditionally related to psychological distress, in medical parlance the term described an evident symptom induced by abnormal, unstable psychic conditions. In contrast, Bonnie Bainbridge Cohen eliminates the pathological and psychological presumptions, to place it at the core of the identification of her practice in the somatic field. In Introduction to Body-Mind Centering ${ }^{\circledR}$ she notes:

I use the word 'somatisation' to engage the kinaesthetic experience directly, in contrast to 'visualization', which utilizes visual imagery to evoke a kinaesthetic experience. Through somatization, the body cells are informing the brain as well as the brain informing the cells. I derived this word 'somatization' from Thomas Hanna's use of the 
word 'soma' to designate the experienced body in contrast to the objectified body. When the body is experienced from within, the body and mind are not separated but are experienced as a whole. [...] Tom [Hanna] spoke of this during the '60 [and] coined the term 'somatics' in 1976 [...]. 'Somatics' also names a field of study - the study of the body through the personal experiential perspective. Body-Mind Centering is a small part this burgeoning field (Cohen, 2012, p. 1).

Cohen's research brought to the field of somatic education several improvements, whose outline is beyond the scopes of this paper. Nevertheless, Eddy sees her as a pivotal figure for the introduction of ecologic instances in the second generation of practitioners (see note 13), to whom the development of a somatic approach through practice became the priority.

In contrast, in Hanna's perspective, the notion of soma remained the simulacrum of Somatics' cultural and political uniqueness, within its flourishing and rather unbridled spread during the 1970s and 1980s. Later on, with the circulation of Hanna Somatics ${ }^{\circledR}$, depicting physiological discoveries through successful somatic diagnosis and treatments became a priority, as it had been for Alexander and Feldenkrais (Ginot, 2010, p. 15-17). Reporting empiric experiences of care did not just provide explanations of somatic theories and practices. It also implied a claim to authority over traditional methods, highlighting how and why these were failing (Hanna, 2004). Anatomical categories and experiential evidence (the competitors' weapons) were successfully chosen as a strategy of legitimation, completing the appropriation of scientific rhetoric:

[...] the somatic viewpoint must be added to the objective bodily viewpoint if we are to understand exactly what happens to human beings as they age. By adding the somatic viewpoint to our human sciences, we not only become capable of overcoming major health problems mistakenly attributed to aging, but we are capable of overcoming many of the major health problems that plague all of humankind. In saying this, there is absolutely no implication that physiological science is invalid. [...] What I am saying is that this contribution is, even so, incomplete and insufficient, and that this is dearly seen in the perennial incompleteness of medical diagnosis and the insufficiency of medical treatments in the areas I am discussing. The somatic viewpoint complements and completes the scientific view of the human being, making 
it possible to have an authentic science that recognizes the whole human: the self-aware, self-responsible side as well as the externally observable 'bodily' side. Together, these two viewpoints make possible an authentic human science. By completing a viewpoint of human beings that has, for so long, suffered from incompleteness, we will set foot on a new continent of human advancement (Hanna, 2004, p. 21).

These were lines published in Hanna's volume on his Somatic Education system in 1988. That year IMTA was founded and soon it would give birth to the International Somatic Movement Education and Therapy Association. The experience of a growing community of practitioners, students, and followers seemed solid enough to estimate that the hardest part of the battle for legitimation had been fruitful; Somatics was becoming a collective, institutionalized entity, entertaining more and more relations with the arts and the life sciences. Thus, it could begin to present itself as a recognizable and valuable approach, as well as demand straightforwardly a more cooperative interaction with healthcare and education systems. Even so, the essentialist tendencies would have consequences in the conception of practice, inhibiting the instance of rupture and ( $r$ )evolution Hanna aimed at promoting.

\section{Somas on Trial}

Though consciously entailing a simplification of the phenomenon, it is possible to advance that, since the early years of the $20^{\text {th }}$ century, two main approaches were generally adopted in the first generation of somatic practitioners. Hanna's method, as well as Feldenkrais' and others', involved both direct manipulation and a system of sequences of exercises that supposedly everyone could do, even on their own. In an individual session, the practitioner would accompany movements or readjust postures through a light contact, making sure that the client would first and foremost feel comfortable and relaxed. In a collective session, or even using a reader, the simplicity of the exercises - as well as their individual execution - would allow following the practitioner's words, without any visual example imposing the right way to do it. Nevertheless, a scale of values (from bad to good gestures) was already predetermined within the discourse and it seems to endure in contemporary studies. 
As recently alluded by Shusterman (2008), a proper somatic exercise is supposed to be done gently, slowly, with delicacy (Ginot, 2010, p. 2022). Moreover, each sequence of exercises should be repeated several times in the same session, and avoiding any precise aim but sensing. If well executed, exercise combined with subjective experience would induce awareness of the structures and perceptions in motion; hence, somatic reorganization would occur. Such systems may be considered the more structural and traditional ones, directly descending from $19^{\text {th }}$ century medical and pedagogical protocols (Schwartz, 1992; Vigarello, 2004), involving the enhancement of proprioception and kinesthesia.

The presumed neutrality and freedom of the care conditions, the unquestionable rightness of the laws of physics and physiological correspondences seem to re-enact, at least in the writings, the aseptic environment of medical approach. Similarly, the moral authority of the somatic practitioner is reaffirmed, though in a subtle way. In fact, in the pioneers' writings no space seems to be left for a selfquestioning of neither the technique nor the approach. Subsequently, any absence of positive results would implicitly lead to point to the client's incapacity or unwillingness to exercise, more than causing to question the means and the presumed universal efficacy of the method. To this day, issues of scientific authority remain unsolved in Somatic Studies, mainly because of lack of theoretical treatment of the matter ${ }^{\mathbf{1 6}}$. This open issue will eventually lead this article to some inevitably non-exhaustive conclusions.

In the previous sections, some features of somatic dogmatism have been introduced, as well as the criticism and dissent that recent activism has been demonstrating from the early 2000s. The main and persisting problem, which I attempted to depict in nuce, is an essentialist posture towards the essence of the living body, which I have also tried to rely to a dogmatic scientific rhetoric since the foundation of the somatic movement and the somatic field by Thomas Hanna (1970, 1976). In fact, most part of the pioneering writings and more recent experiences of practical application seem to enact an authoritarian rhetoric nature of truth within what Donna Haraway would define as situated knowledges (Haraway, 1988, p. 577) Once more, Eddy's overlook of the issue helps to summarize the most important concerns: 
[...] Hanna also notes that in the late twentieth century dualism has been challenged by the notion of the complementarity of structure and function. He adds that these relationships are in a state of constant change as is the soma and that this process of change is self- governed. The ever-changing and self-governing process of the individual soma is a given, which - perhaps mistakenly, leads to a notion that an orientation to the individual versus its cultural context is central in somatic practice [...] Continuing with this Eurocentric discourse, he goes on to argue that somatic theory has also allowed a greater Western acceptance of Asian movement practices (Eddy, 2002, p. 48).

Eddy's lines eventually reflect Ginot's considerations on soma as a culturally-determined entity, which by a post-colonial and feminist perspective converges with Haraway's notion of cyborg (Ginot, 2010, p. 23-26). A coherent orientation of this perspective can be achieved by retracing the cultural-historical roots of the somatic discourse within the $19^{\text {th }}$ and $20^{\text {th }}$ century scientific rhetoric and pedagogic traditions. Through their works, Hillel Schwartz and Georges Vigarello help to profile a broad sociocultural background in which the early Somatics dogmatism may be inscribed. The scholars explain how the endurance of the authoritarian function on bodily exercise may be stretched throughout the modern and contemporary era. In so doing, they also contribute to place the early somatic approach in a perspective of continuity. With the advent of the industrial era physical education began, on one hand, to pursue a strong mechanization of the protocols and a normalization of the social roles through practices such as gymnastic and posture correction (Vigarello, 2004). On the other, especially from the late years of the $19^{\text {th }}$ century, several scientists and pedagogues began to respond to such approach - which was depicted as objectifying - with a more humanitarian, paternalistic attitude (Schwartz, 1992; Vigarello, 2004). Thus, bodily practice acquired new moral values and aimed to shape a righteous, efficient attitude together with a performing body. Eventually, individual exercise and strong self-discipline informed the bio-politic side of the libertarian Euro-American culture from the second half of the $20^{\text {th }}$ century ${ }^{17}$.

For more than two centuries, the practitioner's authority has been shifting among direct correction, prescription, and moral judgment without ever really dismissing any of these instances, even 
when authorizing or empowering self-discipline. By this perspective, Somatics risks expressing but a further form of emancipation of the client's individuality and free choice in the context of dominant values and free market. If not so, what really seems to operate the rupture and the evolutionist revolution the pioneers and Hanna spoke of? Is activism really supposed to dismiss the continuity with $19^{\text {th }}$ and $20^{\text {th }}$ century protocols and the mainstream medical and education systems, or provide an alternative to their ethical posture? How can somatic education contribute to such political action?

\section{Conclusions: how does Somatics become somatic?}

To our days, the somatic field is constituted by a composite heritage of both techniques and theories, aiming at assuring individual emancipation from traditional healthcare protocols. The individualistic paradigm claims for subjectivity as a legitimized cognitive mode in healthcare and education. Yet, it also represents a functional fiction, one among several discursive strategies that the somatic founders adopted in order to validate their practice, both in the scientific field and on the market. Thus, somatic disciplines are ambiguously placed between the support of subjective and community self-improvement (and the appropriation of situated knowledge) and some fundamental authoritarian ideologies concerning bodily representations and social interaction. Coming from a middleclassed, generally male-gendered point of view, bodily mapping in early somatic writings often reveals strong ethnocentrism, and do not question gender issues or social difference. Ginot efficaciously resume these points:

Separated from their usual contexts, somatic discourses are mobilized by thoughts of the universal. They are freighted with innumerable ideologies: the natural (indeed, the animal), the transcendent (indeed, the religious), the biological difference of the sexes, and cultural hierarchies [and create] a system of reference centered on itself. [...] behind the insistence on the singularity of each corporeality, most somatic methods have as a backdrop a homogeneous, universal, ahistorical, and occidental body (Ginot, 2010, p. 23).

Nevertheless, Somatic Education is presently transforming through a more conscious critical approach. Of course, it is supported by flourishing scientific literature - from cognitive to neurosciences, 
from quantum theories to psychology, from pedagogy to Gender Studies - and the wish of a consistent, mutual exchange may become true. Yet the battle between external and inner dogmatism is far from being won. The contradictory coexistence of such tendencies is both, of course, a consequence of its libertarian ethics and the result of the ambiguities I have tried to outline. Thus, how Somatics will respond to further sociocultural change is a matter of ethics and methodology, which should promote a radical reinvention of the narrative of subjective experience. Currently, assuming that Somatics' imprint on the human being's development becomes visible only through time, Social Somatics ${ }^{18}$ and other forms of activism are concerned with collective issues, trying to shift their point of view from the individualistic implications of the soma to the interdependence of cognitive processes with the environment. This could offer an alternative horizon to the definition of the field. Otherwise, as I tried to outline, Somatics risks representing itself by, and endeavouring, a repertoire of recurrent paradigms and examples, instead of rules - a groundwork "[...] which gives [to somatic practitioners] a working knowledge without the ability to explain how it works ${ }^{19}$ " (Kuhn, 1962/1996 apud Ginot, 2010, p. 17).

As Ginot has pinpointed a further issue at stake is the complexity that the notion of body, as soma or embodied person, has acquired in the last two decades (Ginot, 2010, p. 23-26). Consciously or not, bodily physical and epistemological transformation seems to accelerate exponentially, endeavoured by technologies, a growing market and a gradual recognition by the institutions. 


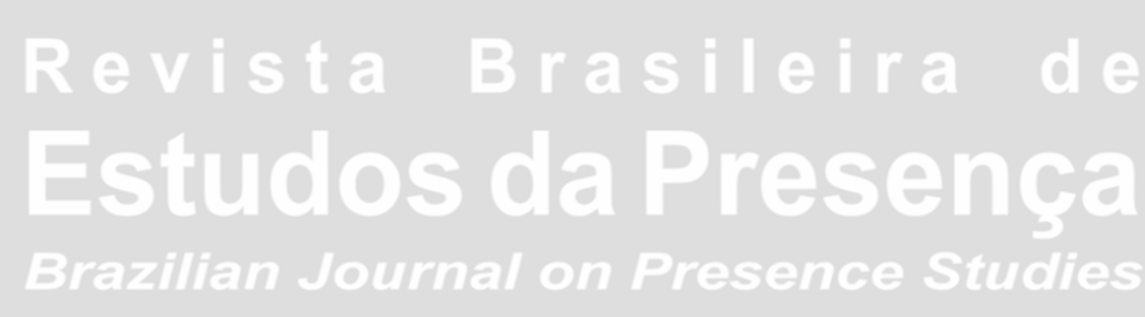

\section{Notes}

${ }^{1}$ English translation of Savoirs Somatiques, notion currently adopted by Isabelle Ginot in her lectures. Ginot is Professor at the Département Danse, Université Paris 8, France, as well as a Feldenkrais practitioner. Since 2007, Ginot has been directing Soma\&Po. Somatiques, Esthétiques, Politiques, an axis of research devoted to somatic research and epistemology. I will often recall her studies throughout the text.

${ }^{2}$ These last topics, in particular, are currently scattered in several studies and lack cohesion in their theoretical treatment. I will thus use some French studies as a background, and refer to Ginot's definition of Somatics as "[...] a conceptual apparatus that enhances our understanding of pedagogy, dancer's health, and corporeal and gestural aesthetics [and which] presents itself as an empirically based mode of bodily thinking whose discourse rely strongly on oral tradition" (Ginot, 2010, p. 12-13). Such disciplines - which will be expounded in the next chapters - are mainly current in developed (so-called Western) countries. Often they intertwine with a variety of niches in the arts, in physical practice, education, and healthcare concerned in holistic approaches. They usually understand themselves as complementary or alternative to dominant protocols - namely, medical and psychoanalytical traditions, as well as pedagogy and bodily aesthetics (Ginot, 2010, p. 12-18).

${ }^{3}$ Isabelle Ginot defines as endogenous somatic discourses those which are developed within a context of somatic practice. They are usually addressing to clients (or patients) as well as to disciples and based on, or engaged by the founders of somatic methods, in order to explain the nature of their work and values. The circulation of great part of these discourses takes place orally, while the somatic founders' writing remain the main reference in both general public and the community of practitioners (Ginot, 2010, p. 13).

${ }^{4}$ Martha Eddy (Registered Somatic Movement Therapist, Certified Movement Analyst, Director of the Dynamic Embodiment Somatic Movement Therapy Training - DE-SMTT) is an American somatic practitioner, activist, and researcher. She obtained a Ph.D. in dance science and education at the Teachers College, Columbia University (1998), and trained with Bonnie Bainbridge Cohen in Body-Mind Centering ${ }^{\circledR}$ as well as with Ingmard Bartenieff in Bartenieff Fundamentals. Eddy is currently based in New York, where she founded the Center for Kinesthetic Education (CKE) and leads her own Somatic Movement Education program. She is also the funding co-director of the Moving On Center - The School of Participatory Arts and Research in Oakland, California. Further information is provided in the CKE website.

${ }^{5}$ According to Ginot, the published texts belong to the third sphere of production of somatic discourse in endogenous writings, including the founding practitioners' writings. These texts mainly endeavor the legitimation of their practice and knowledge by scientific discourse and, or, experiential narrative. Interestingly, Ginot adds: "The need to reduce these two apparently polar models to a single usage or function constitutes the most prominent paradox in somatic discourse. Thomas Hanna (1995) and Carl Ginsburg (1996) have described this paradox in terms of conflict between objective and subjective description, questioning the compatibility of the 'scientific' and objective approach to the subjective 


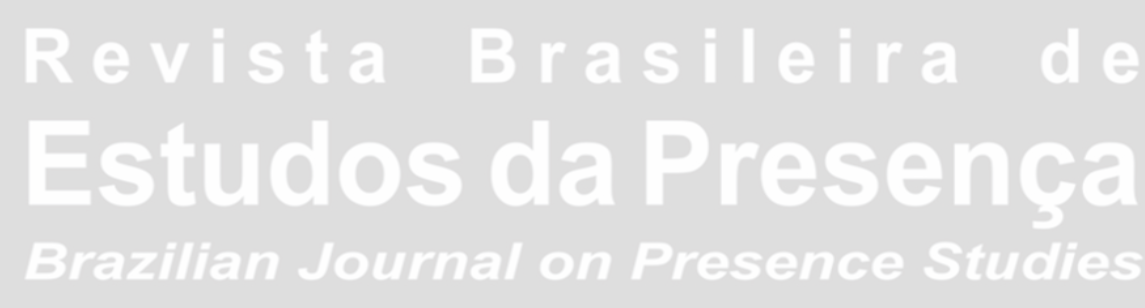

knowledge of Somatics. But they did so with regards to the relationships between the sciences and Somatics, and their observations missed the contradiction internal to somatic discourses" (Ginot, 2010, p. 18).

${ }^{6}$ Ginot's recalls Basile Doganis' position, based on an inquiry of the theorization in martial arts, according to which "[...] belief is part and parcel of the somatic gesture itself" (Ginot, 2010, p. 18). However, it has to be noted that in my analysis, Ginot's strict correspondence between somatic writings and body techniques is less immediate or, at least, evident. In fact, the texts I will approach are not oriented to outline the functioning of specific practices, yet those which constitute the background of their authors inevitably interfere in the discourse.

${ }^{7}$ The analysis and even speculation on the features of possible, unrealized organizations of the somatic field is beyond the limits of this text. Nevertheless, I can find a great number of topics that would take advantage from a punctual analysis. Among many others, several issues are related to gendered biases concerning body image, protocol standards or even good movement (Ginot, 2010, p. 20-21); the interferences of capitalistic and colonial economies in the management of Somatics internal and heterogeneous sources; the implicit hierarchy within the somatic practices, according to the authority of the founders and the degree of exposure to those means enabling one discipline to successfully cope with both the market and the scientific field.

${ }^{8}$ The foundation of the field hails to 1976, together with the first issue of The Somatics Magazine - Journal of the Bodily Arts and Sciences (Hanna, 1976, p. 32). Hanna's exclusive paternity is generally accepted as a fact. Moreover, the absence of any substantial integration of his definitions of soma and Somatics until very recent years seems to signal an implicit unquestioned acceptance of Hanna's paradigms.

9 Recalling once more Ginot's inquiry, they can be resumed as essentialist positions on the organic, natural dimension of the body (Ginot, 2010, p. 23); on the authority of the master and the scientific functional reference - roles that in Hanna seem to converge; on the nature of Somatics itself, as a subjective modality of scientific knowledge which can be abstracted from its situated context of production. A recent, very relevant case Ginot considers is Richard Shusterman's somaesthetics (Shusterman, 2008; Ginot, 2010, p. 20-22), which I will refer to later on in the text.

${ }^{10}$ The most recurrent methods in the writings involved in the definition of Somatics as a field - from Hanna's to Ginot's and Shusterman's - are the Feldenkrais Method and the Alexander Technique, followed by Body-Mind Centering ${ }^{\circledR}$, which is significantly pivotal in Eddy's perspective.

${ }^{11}$ The quote opens the section "Intentions" of this article. The missing line is interposed between the first sentence and the question Eddy asks to herself.

${ }^{12}$ An explicit reference to Lakoff in a more recent article (Eddy, 2010, p. 2) seems also to confirm the coherence of this connection.

${ }^{13}$ The second generation groups dancers and practitioners, such as Anna Halprin, Nancy Topf, Bonnie Bainbridge Cohen, Sondra Fraleigh, Emilie Conrad, Joan Skinner, Elaine Summers, and Judith Aston. Partially extending Hanna's list, Eddy also refers to a number 


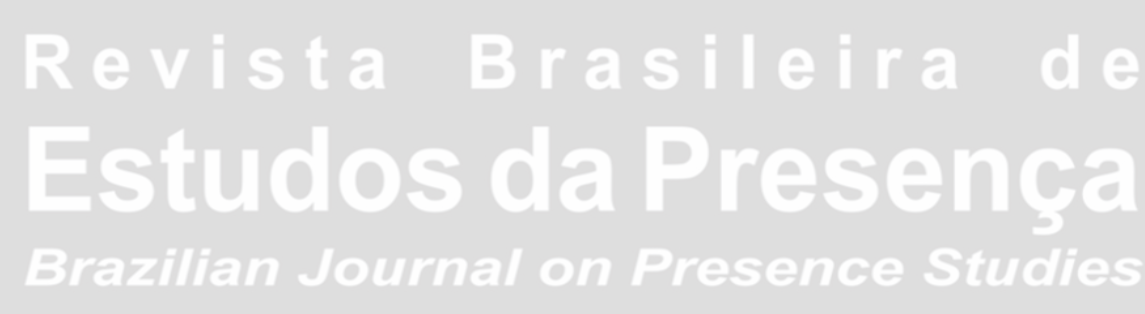

of practitioners (Frederick M. Alexander, Moshe Feldenkrais, Mabel Todd, Irmgard Bartenieff, Charlotte Selver, Milton Trager, Gerda Alexander, and Ida Rolf) as "the somatic pioneers" (Eddy, 2009, p. 12).

${ }^{14}$ Hanna outlines the researches of Charles Darwin, Sigmund Freud, Konrad Lorenz, Jean Piaget, Wilhelm Reich as belonging to the former group, while Immanuel Kant, Søren Kierkegaard, Karl Marx, Ernst Cassirer, Albert Camus, Maurice Merleau-Ponty, Friedrich Nietzsche are similarly examined and referred to the latter.

${ }^{15}$ In a teaching session of Awareness Through Movement ${ }^{\circledR}$ in the South Bend Workshop, Feldenkrais would significantly state: "Good posture is a biological necessity" (Feldenkrais, $1980 b$, n. p.).

${ }^{16}$ A punctual analysis of the relationship between the approaches profiling in the practitioner's writings and the configuration of the practice may be interesting subjects for further researches.

17 Susan L. Foster traces a similar tendency of managing difference in modern and contemporary post-colonial society, involving practices and corporeal representations in several dance aesthetics and training systems (Foster, 2010).

18 "As educators, there are numerous points to consider in creating a 'Social Somatics' curriculum or a dance or movement course with a 'social Somatics' point of view. Some possibilities include: 1. Consciously determine when the uses of Euro-centric models of health (e.g., language of anatomical sciences) are useful or limiting for the larger goals at hand. 2. Provide readings from the early thinkers of somatic theory and the proponents of 'Social Somatics' (e.g., Green, Hanna, Johnson, Kleinman). 3. Seek to develop programs that cite the underlying influences within the somatic theories. The strong influence of Eastern philosophies is most notable. [...] 6. Give students opportunities to share their 'lived' or embodied knowledge through and at performances, in classes and at home [...]. Take a cue from qualitative educational research to observe astutely and 'Hear Students' voices" (Eddy, 2000, p. 5-6). A collection and evaluation of the outcomes of American and European studies and activism may provide a relevant enhancement of the present research.

${ }_{19}$ In his essay Body Consciousness: a philosophy of mindfulness and somaesthetics (2008), Richard Shusterman adopts a very similar posture and methodology by engaging a somaesthetic inquiry of several philosophers, namely Michel Foucault, Simone de Beauvoir, and Maurice Merleau-Ponty. Shusterman encounters Ginot's scepticism and evaluation in terms of abstraction of the somatic discourse from its contingencies. As a matter of fact, the recurrence of such discursive strategies signals a similar essentialist somatic position. Marked by an obsessive intention to define and apply somatic paradigms, "[...] the temptations of proof" (Ginot, 2010, p. 18) stretch from Hanna to Shusterman and constitute a seemingly seductive modality to organize the discourse.

\section{References}

ALEXANDER, F. Matthias. Man's Supreme Inheritance: conscious control and guidance in relation to human evolution in civilization. London: Methuen \& Co., 1946 [1910]. 
ALEXANDER, F. Matthias. The Universal Constant in Living. London: Mouritz, 2000 [1942].

ALEXANDER, F. Matthias. The Use of the Self: its conscious direction in relation to diagnosis, functioning, and the control of reaction. London: Orion Books, 2001 [1932].

BOTTIGLIERI, Carla. Soigner l'Imaginaire du Geste: pratiques somatiques du toucher et du mouvement. Chimères: revue des schizoanalyses fondée par Gilles Deleuze et Félix Guattari, n. 78, p. 113-128, 2013.

BOTTIGLIERI, Carla; GINOT, Isabelle; SALVATIERRA, Violeta. Du Bien être au Devenir Subjectif. In: FLORIN, Agnès; PRÉAU, Marie (Ed.). Le Bien Être. Paris: L'Harmattan, 2013. P. 247-257.

COHEN, Bonnie Bainbridge. Sensing, Feeling, and Action: the experiential anatomy of Body-Mind Centering ${ }^{\circledR}$. Northampton: Contact Editions, 2012 [1993].

EDDY, Martha. Access to Somatic Theory and Applications: socio-political concerns. In: CRONE-WILLIS, Juliette. Dancing in the Millennium: an international conference. Washington, D.C.: [s.n.], 2000. P. 144-148. Available at: <http:/www.wellnesscke.net/ downloadables/Access-to-Somatics.pdf>. Accessed on: 03 Oct. 2014.

EDDY, Martha. Somatic Practices and Dance: global influences. Dance Research Journal, v. XXXIV, n. 2, p. 46-62, autumn 2002. Available at: <http://www.wellnesscke.net/articles/ globalinfluences.pdf>. Accessed on: 03 Oct. 2014.

EDDY, Martha. A Brief History of Somatic Practices and Dance: historical development of the field of somatic education and its relationship to dance. Journal of Dance and Somatic Practices, v. I, n. 1, p. 5-27, spring/summer 2009.

EDDY, Martha. The Role of the Arts \& Embodiment in Community Building: a post 9/11 review. Currents, Northampton, Body-Mind Centering Association, v. 13, n. 1, p. 1-10, winter 2010. Available at: <http://www.wellnesscke.net/downloadables/ ARTSCOMMUNITYINTRAUMAEDDY2010.pdf>. Accessed on: 05 Oct. 2014.

FELDENKRAIS, Moshe. Awareness through Movement: health exercises for personal growth. London: Penguin Books, 1980a [1972].

FELDENKRAIS, Moshe. The South Bend Workshop: 1980 - awareness through movement ${ }^{\circledR}$. Berkeley: Feldenkrais Resources, $1980 \mathrm{~b}$.

FELDENKRAIS, Moshe. The Elusive Obvious or Basic Feldenkrais. Capitola: Meta Publications, 1981.

FORTIN, Sylvie; VIEIRA, Adriane; TREMBLAY, Martyne. The Experience of Discourses in Dance and Somatics. Journal of Dance and Somatic Practices, v. I, n. 1, p. 47-64, spring/summer 2009.

FORTIN, Sylvie; LONG, Warwick; LORD, Madeleine. Three Voices: researching how somatic education informs contemporary dance technique classes. Research in Dance Education, v. III, n. 2, p. 155-179, summer 2002. 


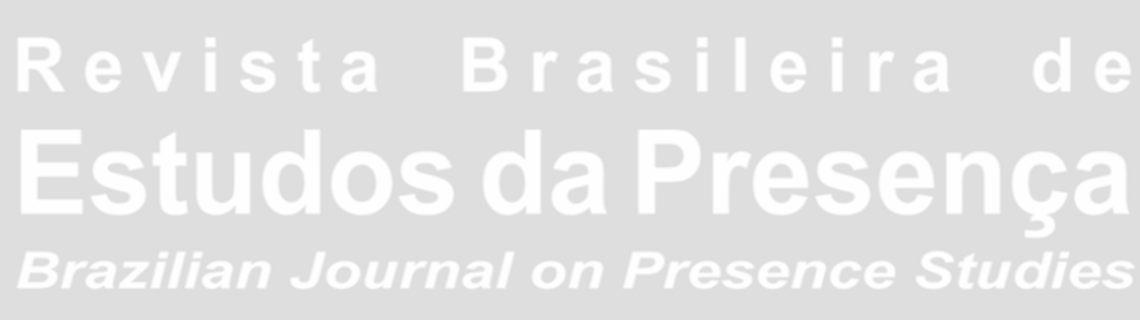

FOSTER, Susan Leigh. Choreographing Empathy: kinesthesia in performance. London/ New York: Routledge, 2011.

FOUCAULT, Michel. Usage des Plaisirs et Techniques de Soi. In: FOUCAULT, Michel. Dits et Ecrits: 1976-1988. v. II. Paris: Gallimard, 2001 [1984]. P. 1358-1380.

GINOT, Isabelle. Discours, Techniques du Corps et Technocorps. In: GIOFFREDI, Paule. A la Rencontre de la Danse Contemporaine: porosités et résistances. Paris: L'Harmattan, 2009. P. 265-293.

GINOT, Isabelle. From Shusterman's Somaesthetics to a Radical Epistemology of Somatics. Dance Research Journal, v. 42, n. 1, p. 12-29, summer 2010. Available at: <http://www. danse.univ-paris8.fr/chercheur_bibliographie.php?cc_id=4\&ch_id=11>. Accessed on: 05 Oct. 2014.

GINOT, Isabelle. Body Schema and Body Image: at the crossroad of somatics and social work. Journal of Dance and Somatic Practices, v. III, n. 1\&2, p. 151-165, 2012. Available at: <http://www.danse.univ-paris8.fr/chercheur_bibliographie.php?cc_id=4\&ch_id=11>.Accessed on: 05 Oct. 2014.

GINOT, Isabelle. Écouter le Toucher. Chimères: revue des schizoanalyses fondée par Gilles Deleuze et Félix Guattari, n. 78, p. 87-100, 2013.

GUATTARI, Félix. The Three Ecologies. Translation: Ian Pindar and Paul Sutton. London: Continuum, 1989.

HANNA, Thomas. The Project of Somatology. Journal of Humanistic Psychology, v. XIII, n. 3, p. 3-14, July 1973.

HANNA, Thomas. The Field of Somatics. Somatics: magazine-journal of the bodily arts and sciences, v. I, n. 1, p. 30-34, autumn 1976. Available at: <http://somatics.org/library/ htl-fieldofsomatics.html>. Accessed on: 02 Oct. 2014.

HANNA, Thomas. The Somatic Healers and the Somatic Educators. Somatics: magazinejournal of the bodily arts and sciences, v. I, n. 3, p. 48-52, autumn 1977. Available at: <http://somatics.org/library/htl-somatichealed.html>. Accessed on: 02 Oct. 2014.

HANNA, Thomas. Bodies in Revolt: a primer in somatic thinking. Novato: Freeperson Press, 1985 [1970].

HANNA, Thomas. Selections from... Somatology: somatic philosophy and psychology. Somatics: magazine-journal of the bodily arts and sciences, v. VIII, n. 2, p. 14-19, spring/ summer 1991a. Available at: <http://somatics.org/library/htl-somatology.html>. Accessed on: 02 Oct. 2014.

HANNA, Thomas. Beyond Bodies in Revolt. Somatics: magazine-journal of the bodily arts and sciences, v. VIII, n. 2, p. 22-27, spring/summer 1991b. Available at: <http://somatics. org/library/htl-beyondbodrev.html>. Accessed on: 02 Oct. 2014.

HANNA, Thomas. A Conversation with Thomas Hanna, Ph.D. by Helmut Milz, M.D. Somatics: magazine-journal of the bodily arts and sciences, v. VIII, n. 2, p. 50-56, spring/ summer 1991c. Available at: <http://somatics.org/library/mh-hannaconversation.html >. Accessed on: 02 Oct. 2014. 
HANNA, Thomas. What is Somatics? In: JOHNSON, Don H. Bone, Breath and Gesture: practices of embodiment. Berkeley: North Atlantic Books, 1995. P. 341-332. Available at: <http://somatics.org/library/htl-wis1.html>, <http://somatics.org/library/htl-wis2. html>, <http://somatics.org/library/htl-wis3.html>, <http://somatics.org/library/htl-wis4.html>. Accessed on: 02 Oct. 2014.

HANNA, Thomas. Somatics: reawakening the mind's control of movement, flexibility, and health. New York: Da Capo Press, 2004 [1988].

HARAWAY, Donna. Situated Knowledges: the science question in feminism and the privilege of partial perspective. Feminist Studies, v. XIV, n. 3, p. 575-599, autumn 1988. HARAWAY, Donna. Simians, Cyborgs, and Women: the reinvention of nature. New York: Routledge, 1991 [1990].

LAKOFF, George. Women, Fire, and Dangerous Things: what categories reveal about the mind. London: University of Chicago Press, 1987.

LAKOFF, George; JOHNSON, Mark. Metaphors we live By. London: University of Chicago Press, 1980.

SCHWARTZ, Hillel. Torque: the new kinaesthetic of the 20th century. In: CRARY, Jonathan; KWINTER, Sanford. Incorporations. v. VI. Cambridge/New York: Zone/ MIT Press, 1992. P. 70-127.

SHUSTERMAN, Richard. Body Consciousness: a philosophy of mindfulness and somaesthetics. New York: Cambridge University Press, 2008.

STENGERS, Isabelle. Cosmopolitiques. v. I. Paris: La Découverte, 2003.

VARELA, J. Francisco; THOMPSON, Evan; ROSCH, Eleanor. The Embodied Mind: cognitive science and human experience. Cambridge/London: MIT Press, 1993.

VIGARELLO, Georges. Le Corps Redressé. Paris: Armand Colin, 2004 [1978].

VIGARELLO, Georges. Histoire du Corps: 1. les mutations du regard - le XXe siècle. Paris: Seuil, 2006.

WEBER, Rebecca. Integrating Semi-structured Somatic Practices and Contemporary Dance Technique Training. Journal of Dance and Somatic Practices, v. I, n. 2, p. 237254, 2009.

WILLIAMSON, Amanda. Formative Support and Connection: somatic movement dance education in community and client practice. Journal of Dance and Somatic Practices, v. I, n. 1, p. 29-46, 2009. 
Margherita De Giorgi is a Ph.D. candidate at the Department of Arts, Università di Bologna, and at École Doctorale Esthétique, Sciences et Technologies des Arts (EDESTA), Département Danse, Université Paris 8. Her research focuses on Somatics and performance, with regards to the notion of presence and its configurations on stage. Further studies are devoted to European butoh (2014, forthcoming). She is a member of the editorial board of Antropologia e Teatro, Università di Bologna journal. E-mail: margheritadegiorgi.mdg@gmail.com

This unpublished text, revised by Ananyr Porto Fajardo, is also published in Portuguese in this issue.

Received in May 31', 2014 Accepted in September ${ }^{\text {th }}, 2014$ 